\title{
Systems Analysis in the Study of the Political Elite
}

\author{
Nadezhda Ponomarenko \\ The Russian Presidential Academy of National Economy and Public Administration, Novosibirsk, Russia
}

\begin{abstract}
The main topic of the research is applying of systems approach in studying of political elite. This approach was applied in the analysis of Russia's regional power elite (1991 to 2010). The elite was studied as a complex self-reference system oriented at its own environment, not only in an adaptive way, but first and foremost in structure. The systems approach specifies the following conceptual framework of the study: self-reference, system boundaries, and interaction between the political elite and the surrounding world. Application of the systems analysis to studying the political elite enabled to analyze the structure and functions of the elite, create a model of elitogenesis, and receive study matrix.
\end{abstract}

Keywords: political elite system, self-reference, boundaries of the political elite, political elite, systems analysis, structure of political elite

\section{Introduction}

The power elite is one of the most important factors in the political process. Changing of the elite structure, its role, and significance in the public system requires applying new methods of analysis, since the former approaches were not always functional for solving newly emerging problems. In the paper, the systems approach is proposed in the studying of the political elite. Application of the systems analysis to studying the political elite enabled to analyze the structure and functions of the elite and create a model of elitogenesis (Ponomarenko, 2013). Studying the political elite as a system but not merely a social group allowed to substantially broaden the scope for analyzing it. Analyzing the elites from the viewpoint of the systems theory made it possible to consider the object under study as a complex system existing in the conditions of transformation thereby determining the conceptual framework of the study.

In the first part, the main approaches of studying of political elite are shown. In the second part, the peculiarities of systems approach in studying of political elite are described. In the third part, the limitations of the systems approach are summarized.

\section{Political Elite as a Social Group}

In terms of a conceptual expression, the studies of political elite may be divided into stratificational and transitological, each based on different theoretical premises and methodological approaches. Both of the approaches are related. As the methods of study of the political elite, use was primarily made of the analyses of

\footnotetext{
Nadezhda Ponomarenko, Ph.D., Department of Political Sciences and Technologies of Siberian Institute of Administration, The Russian Presidential Academy of National Economy and Public Administration, Novosibirsk, Russia.

Correspondence concerning this article should be addressed to Nadezhda Ponomarenko, Department of Political Sciences and Technologies of Siberian Institute of Administration, The Russian Presidential Academy of National Economy and Public Administration, Novosibirsk, Russia. E-mail: p-nadezhda@mail.ru.
} 
documents and biographies of elite representatives, as well as semi-formalized profound interviews, expert and mass polls, case-studies, inclusive observation, and others. Within the framework of stratification studies, political elite is treated as a special social group. Principal attention was paid to its specific characteristics, such as structure, mobility (genesis, recruiting, excorporation, and career trajectory), interaction with other social groups, and finally, values and purposes (Kryshtanovskaya, 2004).

In its turn, transitological studies are based on the analysis of the influence of elites upon the processes of transformation of political regime in post-Soviet Russia. Succession and changeability of elites in these studies are considered from the point of view of prospects of democratization and other consequences of a change of the political regime (Duka, 2005).

The researchers treated political elite as a social group. Consequently, they studied the structure of this group, the channels of incorporation and excorporation, but it is noteworthy that the subject of political elite is somewhat wider than a mere social characteristic of the ruling class: In the first place, this problem concerns the peculiarities of the ruling regime, design of the power institutions, prospects of transformation, and directions of transformation of political system.

The method of approach to political elite as a social group makes it possible to characterize the structure, belonging to profession, psychological portrait of the elite, but it is rather problematic to analyze the structure, functions of the political elite, construct a matrix for the comparison of various elite groups, and formulate conceptual and theoretical generalizations.

\section{The System of Political Elite}

In recent study, the systems approach was applied as some theoretical basis of the analysis of political elite. In the study, the political elite was studied as a self-reference system. The system is characterized as a self-reference one, if the elements of which the given system is comprised are organized by the system itself as functional unities, and in all the relations among these elements, the system provides reference to such self-constitution, thereby continuously reproducing it.

The subject of self-reference refers to the problem of system formation; incidentally, it should be pointed out that this subject is getting more and more attention, including such themes as self-reference systems and autopoiesis. In any case, in the theory of systems, the vector is changed, which makes it possible to shift self-attributing from the level of system formation and structure changing to the level of organization elements. The transition to the theory of self-reference systems, in the framework of the general theory of systems possesses certain structural and processual consequences, taking which into account people obtain both a new set of instruments and a point of view at the phenomenon of political elite.

The consequence of transition to the concept of self-reference systems deals with the operative level of systems processes. For the whole aggregation of systems open to the surrounding world, with the transition from self-organization to "autopoiesis", the key problem underlying the theory changes. Up to the point when authors proceeded from the problem of formation and changing of the structures and perceived in it the systems dynamics, the problem consisted in the special conditions in which repetition of a similar action or expectation of its repetition was probable. On the contrary, in the theory of autopoietic systems, in the first turn, there arises a question as how the transition from one elementary event to another occurs; the main problem being, in this case, not repetition, but the ability for joining. So, in the research, the following matrix was used: the structure 
of political elite system, system boundaries, and interaction between the political elite and the surrounding world.

\section{The Structure of Political Elite System}

Political elite is a self-reference system. Self-reference assumes a principle that is designated as the principle of a compound constitution which declines the former idea that the system as a whole of political elite in particular consists only of elements and connections among them. No element can be determined irrespective of the system (Luhmann, 2007). So, the system of political elite considers its elements as such and it qualifies them in connection with this. As a result, the system of political elite can be constituted and changed only by means of the relations of its elements, but not by means of disintegration and reorganization. The system as a unity that cannot be decomposed any further is each time the element (Luhmann, 2007).

The realization of intra-elite connections in consequence of the integrity calls for selection but not mere inclusion of new elements in the system structure. The fact rather unlike that elite systems are formed out of the initial stratum of fairly similar unities may be accounted for by the necessity of selection and by the fact of conditioning by the selection acts. It should be noted that the self-reference, at the level of elements, reproduction of the elite is to secure elements of those kinds that are stipulated by the existing system of relations, thereby ensuring reproduction, which results in setting the boundaries of variations of transformation of the elite structure.

The process of reproduction of the system of political elite can be applied only internally. In other words, the elite structures, unless they are willing to relinquish the foundation of their existence, have to secure the capacity for attaching reproduction, which limits the range of feasible changes within the framework of the system.

The system of political elite that has at its disposal in its own structures and processes is capable of subordinating to these forms of strengthening of selectivity all the elements that are produced and reproduced by it. As a result, it will be able to regulate its own autopoiesis (Luhmann, 2007). However, in the conditions of the surrounding world, this consideration of the whole aggregate of possible elements by means of the forms of strengthening selectivity cannot still have any exclusive applicability. This works merely as the procedure of differentiation, consequently, in analyzing the elite structures, one should take into account the events of deviation, while in respect of intra-elite processes, account should be taken of possible and unrealizable ones.

Political elite structures leave open a limited set of choice possibilities. By means of this selection, the structures can direct further acts of selection, each time reducing the possibilities to visible situations. The processes are realized, due to the fact that particular acts of choice are arranged in time relative to each other, are joined together with each other, and, consequently, the previous selection acts and respectively its expected acts, are built in a separate selection act as its prerequisites (Luhmann, 2007).

It is noteworthy that in the framework of new conceptions of the theory of systems, the structure does not act as such, but is part of the experience of differences (Luhmann, 2007). Thus, the elite system creates its own past as its own causal foundation that allows it to distance from the causal pressure of the surrounding world. As a result, the modus operandi of self-reference elite systems passes on to such forms of causality which to a large degree take the system away from the safe external control.

Elite systems that create their own causality in that case are no longer subject to "causal explanation" (unless in the procedure of the observer's reduction) and the reason lies not only in the lack of transparency of 
their integrity, but due to logical foundations. They assume themselves as the produce of self-reproduction (Luhmann, 2007). The system of political elite may perceive any external influence or external stimulus first and foremost as information, i.e., an experience of difference and in that form fixes it in itself.

The integrity of political elite is reproduced as an inevitable trait at each of the higher levels of formation of the given system. An integrated system of political elite must adapt not only to its surrounding world, but also to its own integrated nature. The system should be able to cope with its internal crises and "challenges", evolve mechanisms that could reduce any deviated behavior, which becomes possible only due to the fact that there exist dominant basic structures (Luhmann, 2007). Consequently, elite, as a self-reference system, has to be self-adaptable, namely, to be able to adapt to its own integrity. This fact explains why elite systems cannot continuously follow changes in its surrounding world even in the conditions of transformation of the regime.

It should be pointed out that the degree of integration of political elite may be different. In the systems theory, systems of higher (emergent) order may possess lower integrity than systems of lower order, since they themselves determine the integrity and the number of elements of which they consist, i.e., in the integrity, they are independent of their real foundation (Luhmann, 2007). It also means that the necessary and respectively sufficient integrity of the political elite system are not determined by the "material" used by the system, but can be determined anew for each system formation level, either in conformity with the relevant surrounding world or with respective political regime.

\section{System Boundaries of Political Elite}

The most important requirement for isolation of the systems, along with the constitution of their own elements is determination of the boundaries. The boundaries may be considered determined enough, if they allow to process problems of behavior of the borderline that remained open or attribute the events either inside or outside, by the system's own means (Luhmann, 2007).

In a general sense, the boundaries of political elite possess a dual function of separation and joining the system and the surrounding world. If the boundaries are determined accurately, the elements may be attached either to the system or to its surrounding world. On the contrary, relations may exist both between the system and the surrounding world. The boundary separates the elements, but not necessarily the relations; it separates the events, but allows causal actions to be realized (Luhmann, 2007). This feature distinguishes the notion of system from the notion of structure.

This, in itself, old and indisputable notion of the boundary is a prerequisite for the latest development of the theory of systems, in which the distinction between open and confidential systems is already perceived not as antipodes of the types, but as a manifestation of strengthening (Luhmann, 2007). With the help of the boundaries, the systems may at the same time close and open, thereby separating the internal interdependences from interdependences system/surrounding world, and connect them with each other. In this respect, the boundaries are predominantly an acquisition of evolution. Any higher development of the system, first and foremost, its development of the systems of internally-closed self-reference assumes the presence of boundaries (Luhmann, 2007).

In the perspective of the dynamics of development, the boundaries act as a factor of amplification. In the system theory, this aspect is designated as the derivative of systems differentiation. Formation of the boundaries interrupts the discontinuity of processes connecting the system with the surrounding world 
(Luhmann, 2007). The discontinuities produced in the process may be fairly regular, allowing the system an opportunity to estimate its contacts with the surrounding world.

The boundaries of the system always cut off the surrounding world; yet, the requirements presented here are changed, if the system in its own surrounding world has to discern other systems (and their surrounding worlds) and determine its boundaries in accordance with that distinction. The relation, in which the boundaries are determined under pressure of the necessity of their input, consequently, the relationship that requires a more accurate determination of their boundaries and their preservation, follows from the above distinction between the aggregate surrounding world and the systems in the surrounding world of the system (Luhmann, 2007).

The notion of a boundary implies that the processes crossing them (for instance, information exchange) proceed in the transition of the system in different conditions (for example, in the conditions of fragmentation or consensus of the ruling elite). One should take into account that the boundaries do not signify any rupture of the connections. In this respect, preserving the boundaries is a condition for retaining the system of ruling elite, since the distinction is a functional prerequisite of self-reference operations.

\section{Interaction Between the Political Elite and the Surrounding World}

In this connection, this paper would like to dwell in greater detail on the difference between the system of political elite and the surrounding world which has deep consequences for understanding the causality within the framework of the system of political elite. The ruling elite as a system is oriented at its own surrounding world not only in an adaptive sort of way, but first and foremost in structure. The political elite systems are constituted and preserved by means of creating and preserving the difference with the surrounding world.

For their part, the systems in the surrounding world of some system are oriented at their surrounding worlds. However, no system can totally control someone else's relations system/surrounding world, if only by way of destruction. Therefore, every system has its surrounding world in the form of an involved complex structure of mutual relations of the system and the surrounding world, and at the same time as a unity constituted by the system itself that requires only selective watching (Luhmann, 2007).

The fact that it is important to differentiate the surrounding world of the system and the system in the surrounding world of the given system is one of the most important consequences of the paradigm system/surrounding world (Luhmann, 2007). So, first and foremost, one should draw a hard and fast line among the relations of dependence between the surrounding world and the system from the relations of dependence among the systems. This distinction undermines the former themes of domination/subordination. Whether the relations in which one system dominates over the other can and how far they can develop not in the last place depend on the situation of dependence of both systems and the system of their relations on the respective surrounding world (Luhmann, 2007).

The line of separation between the system and the surrounding world should not be perceived as isolation and integration of the most important causes in the system; for it, to a much greater degree, slits the causal relationships. Hence, as a result of evolution, a complex of "productive reasons" can be formed, and being once formed, supplement appropriate reasons from the surrounding world (Luhmann, 2007).

\section{Limitations of the Systems Approach}

In the course of the conducted investigation, some limitations of the systems approach have been established. For one thing, the present approach is characterized by a certain degree of reduction. Thus, in 
creating a model of Russia's elitogenesis, the necessity of considerable schematization of the processes under study, as well as some "depersonalization" of the elite was shown. Nevertheless, the efficiency of the systems approach in the study of the political elite is sufficiently high, though the application of the present approach needs further working out as well as discussing in the professional sphere.

\section{Conclusions}

Studying the political elite as a system but not merely a social group allowed to substantially broaden the scope for analyzing it. The systems approach enabled to work out a more flexible and effective theoretical basis for studying political elites at both regional and federal levels. Analyzing the elites from the viewpoint of the systems theory made it possible to consider the object under study as a complex system existing in the conditions of transformation thereby determining the conceptual framework of the study. Applying the systems approach makes it possible to evaluate the political elite structure in its organic unity, as well as to elucidate its functions and evolution features.

\section{References}

Duka, A. B. (2005). The study of elites: The search for theoretical foundations. Power and elites in the Russian transformation. St. Petersburg: Intersonic.

Kryshtanovskaya, O. B. (2004). Anatomy of the Russian élite. Moscow: Publishing House of the A. V. Soloviev.

Luhmann, H. (2007). A social system. An essay of the general theory. St. Petersburg: Nauka.

Ponomarenko, H. A. (2013). The formation of the regional ruling elite in the period of transformation of post-Soviet Russia: Materials of the Siberian macro region. Novosibirsk: Nauka. 